ONDERZOEKSRAPPORT NR 9206

\begin{abstract}
A Branch-and-Bound Procedure for the Generalized Resource-Constrained Project Scheduling Problem

by
\end{abstract}

Erik DEMEULEMEESTER

Willy HERROELEN

$\mathrm{D} / 1992 / 2376 / 9$ 


\title{
A BRANCH-AND-BOUND PROCEDURE FOR THE GENERALIZED RESOURCE-CONSTRAINED PROJECT SCHEDULING PROBLEM
}

\author{
Erik DEMEULEMEESTER \\ Willy HERROELEN \\ Department of Applied Economic Sciences \\ Katholieke Universiteit Leuven \\ Leuven, Belgium
}

Subject classification : Project management : generalized resource-constrained project scheduling. Programming : branch and bound. Networks/graphs : generalized networks. Area of review : MANUFACTURING, PRODUCTION, AND SCHEDULING. 


\section{ABSTRACT}

In this paper a branch-and-bound procedure is described for scheduling project activities subject to precedence diagraming type of precedence relations, ready times, due dates, and variable multiple resource availability constraints, where the objective is to minimize project duration. The procedure is based on a depth-first solution strategy in which nodes in the solution tree represent resource and precedence feasible partial schedules. Branches emanating from a parent node correspond to exhaustive and minimal combinations of activities, the delay of which resolves resource conflicts at each parent node. A precedence based lower bound and several dominance rules are introduced in order to restrict the growth of the solutions tree. The procedure has been programmed in the $\mathrm{C}$ language. Extensive computational experience is reported. 
The specific resource allocation problem addressed in this paper is the generalized resource-constrained project scheduling problem (GRCPSP), in which it is assumed that a project activity is subject to technological precedence diagramming type of precedence constraints (finish-start, finish-finish, start-start and start-finish) and cannot be interrupted once begun (no job preemption allowed). Ready times and due dates can be specified for all activities in the project. Resources are assumed to be available per period in variable amounts and are demanded by an activity in constant amounts throughout the duration of the activity. The objective is to schedule the activities subject to ready times, due dates, precedence relations and resource constraints in order to minimize the total project duration. As such the problem discussed in this paper is an extension of the classical resource-constrained project scheduling problem (RCPSP) which involves the minimization of the project duration subject to the classical finish-start precedence constraints and constant resource availability constraints.

To the best of our knowledge, we are not aware of any open literature that deals with resource-constrained project scheduling problems under the realistic assumptions of other than finish-start precedence constraints, ready times and/or due dates. For the case of variable resource availabilities, Simpson (1991) developed a serial and parallel implicit enumeration algorithm as an extension of the solution procedure presented by Talbot and Patterson (1978) for the classical RCPSP.

The purpose of this paper is to describe a new efficient branch-and-bound procedure for the GRCPSP. The procedure is a major extension of the branch-andbound procedure developed by Demeulemeester and Herroelen (1991) for the RCPSP. It is based on a depth-first solution strategy in which nodes in the solution tree represent resource and precedence feasible partial schedules. Branches emanating from a parent node correspond to exhaustive and minimal combinations of activities, the delay of which resolves resource conflicts at each parent node. The procedure has 
been programmed in the $C$ language and runs on personal computers. Extensive computational experience on two problem sets indicate the procedure to outperform the solution procedures presented by Simpson (1991), both in terms of computational efficiency and effectiveness.

The paper is organized as follows. In Section 1, the GRCPSP is formally defined and a review of the literature is presented. In Section 2, the general concepts of the branch-and-bound solution procedure are introduced. We will prove some theorems that restrict the number of possibilities that have to be explored during the search process. A formal description of the procedure is given together with an illustration of the basic algorithmic steps on a small numerical example. Computational results obtained on two problem sets are presented in Section 3 . The first problem set has been constructed by Simpson (1991) and was based on the wellknown standard Patterson problem set for the RCPSP. The second set is new and is based on variations of one of the most difficult problems in the Patterson set. An indication is given on the impact of adding the various additional constraints to the RCPSP. The last section is reserved for overall conclusions. 


\section{THE GENERALIZED RESOURCE-CONSTRAINED PROJECT SCHEDULING PROBLEM (GRCPSP)}

The classical resource-constrained project scheduling problem (RCPSP) is commonly based on the following assumptions :

(a) A project consists of different activities which are represented in the activity-onthe-node format (i.e. a directed, acyclic graph in which the nodes represent the activities and where the arcs denote the precedence constraints). Two dummy activities are introduced : activity 1 represents the start activity of the project and is a (direct or indirect) predecessor of every other activity in the project, while activity $n$ denotes the end activity of the project and is a (direct or indirect) successor of every other activity in the project.

(b) The activities are related by a set of finish-start precedence relations with a time lag of 0 , implying that no activity can be started before all its predecessors have completed.

(c) No ready times or due dates are imposed on any of the project activities.

(d) Each activity $i(i=1, . ., n)$ has a constant duration $d_{i}$ (setup times are negligible or are included in the fixed duration).

(e) Each activity i requires a constant number of units $r_{i k}$ of a renewable resource type $\mathrm{k}(\mathrm{k}=1, \ldots, \mathrm{K})$. The resource requirements $\mathrm{r}_{\mathrm{ik}}$ are known constants over the processing interval of the activity.

(f) The availability of the renewable resource type $k$, $a_{k}$, is also a known constant throughout the project duration interval.

(g) No activity can be interrupted once begun (activity preemption is not allowed).

(h) The objective is to complete the project as soon as possible without violating any resource or precedence constraints. 
This problem can be conceptually formulated as follows :

$$
\operatorname{minimize} f_{n}
$$

$$
\begin{array}{ll}
\text { subject to : } & f_{i}<=f_{j}-d_{j} \quad \text { for all }(i, j) \varepsilon H \\
& f_{1}=0 \\
& \sum_{i \varepsilon S_{t}} r_{i k}<=a_{k}
\end{array}
$$

where : $\mathrm{n}=$ the number of activities in the project

$\mathrm{K}=$ the number of resource types

$f_{i}=$ the finish time of activity $i$

$d_{i}=$ the duration of activity $i$

$\mathrm{H}=$ the set of pairs of activities indicating finish-start precedence relations

$S_{t}=$ the set of activities in progress during time interval $\left.] t-1, t\right]$

$$
=\left\{\mathrm{i} \mid \mathrm{f}_{\mathrm{i}}-\mathrm{d}_{\mathrm{i}}<\mathrm{t}<=\mathrm{f}_{\mathrm{i}}\right\}
$$

$r_{i k}=$ the amount of resource type $k$ that is required by activity $i$

$a_{k}=$ the total availability of resource type $k$

Reviews of the RCPSP can be found in Herroelen (1972) and Davis (1966, 1973). Numerous researchers have tried to solve this problem using integer linear programming (Bowman 1959, Brand, Meyer and Schaffer 1964, Elmaghraby 1967, McCoy 1972, Moodie and Mandeville 1966, Patterson and Huber 1974, Patterson and Roth 1976, Pritsker, Watters and Wolfe 1969, Wiest 1964), but this solution approach proved to be inefficient. Carruthers and Battersby (1966), Petrovic (1968) and Shackleton (1973), among others, tried to use dynamic programming in order to solve resource-constrained problems, but the 'dimensionality curse' precludes the use of 
dynamic programming as a practical, efficient solution method. However, it can be proven that in order to minimize the project duration it is only necessary to consider semi-active timetabling (French 1982). Timetabling is called semi-active if in the resulting schedule there does not exist an activity which could be started earlier without violating any of the precedence or resource constraints. Consequently, numerous enumerative (branch-and-bound) procedures for solving this problem have been developed (Balas 1970, Bell and Park 1990, Carlier and Latapie 1991, Christofides, Alvarez-Valdes and Tamarit 1987, Davis and Heidorn 1971, Demeulemeester and Herroelen 1991, Johnson 1967, Schrage 1970, Stinson 1976, Stinson, Davis and Khumawala 1978, Talbot and Patterson 1978). Patterson (1984) compared the performance of the exact procedures of Davis and Heidorn (1971), Talbot and Patterson (1978) and Stinson (1976, 1978). On a problem set of 110 problems it was found that the procedure of Stinson was the only one capable of solving all 110 problems, and this in a very small average CPU-time $(0.82$ seconds on an Amdahl 470/V8). Demeulemeester and Herroelen (1991) provide computational evidence that their procedure outperforms Stinson's by a factor of 11.6. Computational experience also indicates that the procedures of Christofides, AlvarezValdes and Tamarit (1987), of Bell and Park (1990) and of Carlier and Latapie (1991) are outperformed on the Patterson problem set by both the procedure of Demeulemeester and Herroelen and that of Stinson. Consequently, the procedure of Demeulemeester and Herroelen (1991) seems to be the fastest exact solution method that is capable of solving the RCPSP.

In this paper some of the assumptions of the RCPSP will be relaxed :

(a) Precedence diagramming is introduced in the following way. Instead of finishstart relations with a lag of 0 , four different types of precedence relations are defined (Moder, Phillips and Davis 1983, page 95): 
$\mathbf{S S}_{\mathbf{i j}}$ : denotes a start-to-start constraint, and is equal to the minimum number of time units that must be completed on the preceding activity i prior to the start of the successor $\mathrm{j}$.

FF $_{\mathbf{i j}}$ : denotes a finish-to-finish constraint, and is equal to the minimum number of time units that must remain to be completed on the successor $\mathrm{j}$ after the completion of the predecessor $\mathrm{i}$.

$\mathrm{FS}_{\mathbf{i j}}$ : denotes a finish-to-start constraint, and is equal to the minimum number of time units that must transpire from the completion of the predecessor $\mathrm{i}$ prior to the start of the successor $\mathrm{j}$. (Note : This is the only type of precedence relation used in the classical activity-on-thenode scheme, with $F S_{\mathrm{ij}}=0$ ).

SF $_{\mathbf{i j}}$ : denotes a start-to-finish constraint, and is equal to the minimum number of time units that must transpire from the start of the predecessor $i$ to the completion of the successor $j$.

The solution procedure that will be described in the next section is applicable only if no activity is allowed to start before one of its predecessors has started (this would for instance be possible if a precedence relation $\mathrm{SS}_{\mathrm{ij}}<0$ was specified). However, this is not a real restriction in project scheduling practice : the notions 'predecessor' and 'successor' already imply that a successor is not allowed to start before one of its predecessors.

(b) Ready times $g_{i}$ and due dates $h_{i}$ can be specified for all activities $i$ in the project. The ready time $\mathrm{g}_{\mathrm{i}}$ indicates that activity $\mathrm{i}$ cannot be started before time $g_{i}$, while a due date $h_{i}$ signifies that activity $i$ should not finish later than at time $\mathrm{h}_{\mathrm{i}}$.

(c) Resource availability akt is now assumed to be variable over the project horizon and thus $\mathrm{a}_{\mathrm{kt}}$ denotes the availability of resource type $\mathrm{k}$ during period ] $\mathrm{t}-1, \mathrm{t}]$. 
This generalized resource-constrained project scheduling problem (GRCPSP) can be expressed in mathematical terms as follows :

$$
\operatorname{minimize} f_{n}
$$

$$
\begin{aligned}
& \text { subject to: } f_{i}-d_{i}+S S_{i j}<=f_{j}-d_{j} \quad \text { for all }(i, j) \varepsilon H_{1} \\
& f_{i}-d_{i}+S F_{i j}<=f_{j} \quad \text { for all }(i, j) \varepsilon H_{2} \\
& f_{i}+F S_{i j}<=f_{j}-d_{j} \quad \text { for all }(i, j) \varepsilon H_{3} \\
& f_{i}+F F_{i j}<=f_{j} \\
& \text { for all }(\mathrm{i}, \mathrm{j}) \varepsilon \mathrm{H}_{4} \\
& \mathrm{f}_{1}=0 \\
& f_{i}-d_{i}>=g_{i} \\
& \mathrm{i}=1, . ., \mathrm{n} \\
& \mathrm{f}_{\mathrm{i}}<=\mathrm{h}_{\mathbf{i}} \\
& \mathrm{i}=1, \ldots, \mathrm{n} \\
& \sum \mathrm{r}_{\mathrm{ik}}<=\mathrm{a}_{\mathrm{kt}} \\
& \mathrm{k}=1, \ldots, \mathrm{K} \text { and } \mathrm{t}=1, \ldots, \mathrm{f}_{\mathrm{n}}
\end{aligned}
$$

where: $\mathrm{H}_{1}=$ the set of pairs of activities indicating start-start relations with a lag of $S S_{i j}$

$\mathrm{H}_{2}=$ the set of pairs of activities indicating start-finish relations with a lag of $\mathrm{SF}_{\mathrm{ij}}$

$\mathrm{H}_{3}=$ the set of pairs of activities indicating finish-start relations with a lag of $F S_{i j}$

$\mathrm{H}_{4}=$ the set of pairs of activities indicating finish-finish relations with a lag of $\mathrm{FF}_{\mathrm{ij}}$

$g_{i}=$ the ready time of activity $i$

$\mathrm{h}_{\mathrm{i}}=$ the due date of activity $\mathrm{i}$

$a_{k t}=$ the availability of resource type $k$ during period $\left.] t-1, t\right]$ 
It should be observed that although we are referring to the single project resource-constrained project scheduling problem, the problem statement easily allows the introduction of multiple projects. As will be demonstrated in the numerical example of section 2.7 , the different projects can be combined into one single project allowing the direct application of a single project procedure.

To the best of our knowledge, we are not aware of any open literature that deals with resource-constrained project scheduling problems in which precedence diagramming, ready times and/or due dates are introduced. The case of variable resource availabilities received somewhat more attention. Simpson (1991) measured the decrease in computation time for the RCPSP when multiprocessor architectures were introduced. He used a parallel algorithm (simulated on a single processor computer system) which required each processor to execute a serial implicit enumeration procedure to solve the RCPSP. The serial procedure implemented by each processor was based on the integer programming algorithm developed by Talbot and Patterson (1978). Simpson took advantage of the extendability of the Talbot and Patterson procedure to devise a serrial and parallel implicit enumeration algorithm for the nonconstant resource availability problem.

In order to gain computational experience on problems where resource availability fluctuates over time, Simpson modified the Patterson test problems in the following way. For each resource type required by a problem, availability levels were reduced at random intervals in the scheduling horizon between period 1 and the period equalling the sum of the activity durations. The number of occurrences of a resource reduction was established as a function of the length of this scheduling horizon. The number of occurrences were uniformly distributed with a mean of one occurrence every 20 periods. The duration of each occurrence of a resource reduction was uniformly distributed between one and five periods. A mild resource reduction consisted of a one unit decrease in the resources available and was assigned a 
probability of 0.75 . A moderate resource reduction of two units occurred with a probability of 0.25 .

The serial procedure was able to optimally solve 97 out of the 110 modified problems, when the procedure was allowed $600 \mathrm{CPU}$ seconds on an IBM 3090. The average computation time for these 97 problems was 100.85 seconds with a standard deviation of 199.62 seconds. The parallel procedure could solve 98 out of those 110 problems and this in an average CPU time of 96.63 seconds with a standard deviation of 195.90 seconds. The computation time for the parallel procedure was obtained through the use of a special program which simulated the effect of parallelism on a single processor computer. The computation time of the simulated parallel program is then obtained by dividing the total solution time by the number of processors that were simulated (Simpson 1991). In the next section we describe a new branch-andbound procedure for the GRCPSP that outperforms the Simpson procedures on the problem set described above. 


\section{SOLUTION METHODOLOGY}

The branch-and-bound procedure to be described in this section is a major extension of the procedure developed by Demeulemeester and Herroelen (1991) for the classical RCPSP. It is based on a depth-first solution strategy in which nodes in the solutions tree represent resource and precedence feasible partial schedules. Branches emanating from a parent node correspond to exhaustive and minimal combinations of activities, the delay of which resolves resource conflicts at each parent node. Before a formal description of the branch-and-bound procedure can be given, a number of definitions are in order. In addition we have to describe the ways in which the suggested procedure bypasses possible anomalies caused by the introduction of precedence diagramming and the ways in which it copes with ready times and due dates. Last but not least, a number of theorems are presented which will allow for a drastic reduction in the search of the branch-and-bound solution tree.

\subsection{Conversion of precedence relations}

The introduction of precedence diagramming can entail some anomalies. De Wit and Herroelen (1990) discuss an anomaly which is caused by the procedure used by commercial software packages to deal with precedence diagramming. Another anomaly is of a more fundamental nature and is explained in Moder et al. (1983). This anomaly, which causes project duration to increase when activity durations decrease, is avoided by converting all precedence relations into finish-start relations. This conversion is always possible because the nonpreemption assumption immediately links the start of an activity to its finish. For any two activities that are linked by at least one precedence relation, the following conversion formula is applied :

$$
F S_{i j}^{\prime}=\max \left\{S S_{i j}-d_{i} ; S F_{i j}-d_{i}-d_{j} ; F S_{i j} ; F F_{i j}-d_{j}\right\}
$$


The logic behind Eq. [14] is apparent and demonstrated in Figure 1. The $S_{\mathrm{ij}^{-}}$ relation, for instance, can easily be converted into an $F S_{i j}$-relation by deducting $d_{i}$ from its lag-value.

Insert Figure 1

\subsection{Ready times and due dates}

The ready time $g_{i}$ of an activity i can easily be transformed into a finish-start relation between the dummy start activity 1 (which starts and finishes at time 0 ) and activity i :

$$
\mathrm{FS}^{\prime}{ }_{1 \mathrm{i}}=\max \left\{\mathrm{g}_{\mathrm{i}} ; \mathrm{FS}_{1 \mathrm{i}}\right\}
$$

Coping with due dates $\mathbf{h}_{\mathbf{j}}$ is somewhat more involved. For every activity $\mathbf{j}$ a latest allowable start time $l_{j}$ has to be computed such that whenever this activity $j$ is delayed to start later than $\mathrm{l}_{\mathrm{j}}$, the due date of this activity or of one of its direct or indirect successors is exceeded even if all subsequent activities were scheduled as soon as possible without considering the resource constraints. Consequently, if during the branch-and-bound procedure an activity $\mathrm{j}$ is assigned an early start time $\mathrm{s}_{\mathrm{j}}$ that exceeds its latest allowable start time $l_{j}$, backtracking can occur as no feasible solution can be found by continuing the search from this partial schedule.

\subsection{The search process}

The description of the search process can depart from the following definitions. Let $A$ denote the $\underline{\text { set }}$ of all activities $i=1, \ldots, n . S_{t}$ has already been defined as the set of activities in progress during time interval $] \mathrm{t}-1, \mathrm{t}$, while the partial 
schedule $\mathrm{PS}_{\mathrm{t}}$ denotes the set of all activities that have been assigned a finish time at time $t$. We define the set of unscheduled activities $\mathrm{NS}_{\mathrm{t}}$ to comprise all activities that have not been assigned a finish time at time $t: N S_{t}=A-P S_{t}$. The set of finished activities $F_{t}$ is defined as the set of all activities that belong to $P S_{t}$ and that have been assigned a finish time that is smaller than or equal to $t$ (those activities have actually been completed at time $t): F_{t}=P S_{t}-S_{t}$. $U_{t}$ then denotes the set of unfinished activities and is defined as $U_{t}=A-F_{t}$. We also define the cutset $C_{t}$ as the set of all unscheduled activities whose predecessors all belong to the partial schedule $\mathrm{PS}_{\mathrm{t}}$. The eligible set $E_{t}$ denotes the set of all activities that belong to the cutset $C_{t}$ and that can start at time t. As in most cases the precise time instant at which these sets are defined will be clear from the context, the subscripts will be omitted for simplicity of notation.

The search process starts by initialising S, PS and C to be empty sets and by adding the dummy start activity 1 to $S$ and PS with a finish time $f_{1}=0$. All activities $i$ that have activity 1 as a single predecessor are added to the cutset $\mathrm{C}$ and are assigned an early start time, based on the precedence relations FS' ${ }_{1 i}$ (which include the ready times). The next decision point $\mathrm{m}$ is then computed as the smallest early start time of any activity in the cutset. The activities in the cutset that can start at time $\mathrm{m}$ are added to the eligible set $\mathrm{E}$. All activities in $\mathrm{S}$ that complete before time $\mathrm{m}$ are deleted from $\mathrm{S}$ and all activities in E are scheduled : they are added to S and PS and are assigned a finish time that equals the sum of the decision point $m$ and the duration of the activity involved. We also immediately update the cutset. If due to the resource constraints it is impossible to schedule all activities in S concurrently, a resource conflict occurs. Such a conflict will produce a new branching in the branch-and-bound tree at level $\mathrm{p}$ : the branches describe ways to resolve the resource conflict; i.e., decisions about which combinations of activities are to be delayed. 
We define a delaving alternative $\mathbf{D}_{\mathbf{q}}$ as a set of activities that belong to $S$, the delay of which would resolve the resource conflict that occurred at level $\mathrm{p}$ of the solutions tree and for which it holds that if an activity belongs to $\mathrm{D}_{\mathrm{q}}$ all its direct and indirect successors that belong to $S$ are also included in $\mathrm{D}_{\mathrm{q}}$. In order to simplify the construction process of the delaying alternatives a precedence relation is added for every activity that can be partially overlapped with one of its indirect successors. As such, only the direct successors need to be examined in order to satisfy the second condition. The delaving set $\mathbf{D}(\mathbf{p})$ then consists of all possible delaying alternatives $\mathrm{D}_{\mathrm{q}}$ that resolve the resource conflict at level $\mathrm{p}$ of the branching tree. For each delaying alternative $\mathrm{D}_{\mathrm{q}}$ the delaving point $\mathrm{w}_{\mathrm{q}}$ is computed as the earliest time at which either the resource availability changes, or an activity that belongs to $\left(S-D_{\mathrm{q}}\right)$ finishes, or one of the unscheduled activities that has no predecessor in $D_{q}$ could finish if all unscheduled activities were scheduled as soon as possible. A precedencebased lower bound $\mathrm{L}_{\mathbf{q}}$ is then calculated by adding the maximal remaining critical path length of any of the activities that belong to $\mathrm{D}_{\mathrm{q}}$ to the delaying point $\mathrm{w}_{\mathrm{q}}$. The delaying alternative with the smallest lower bound is chosen (ties are broken arbitrarily) and these activities are removed from S and PS (as well as all completed successors of one of these activities). All other delaying alternatives are stored for backtracking purposes. The cutset is updated and the process of constructing the eligible set, adding it to $S$ and PS and branching whenever resource conflicts occur is repeated either until a solution to the problem is found or until it can be shown that by branching from this node only infeasible solutions or solutions which would not be better than another one (which could be constructed along a different path) could be generated. When this happens the procedure backtracks.

\subsection{Semi-active timetabling}

As should be clear from the description given above, partial schedules $\mathrm{PS}_{\mathrm{t}}$ correspond to the set of activities that have been assigned a finish time at time t. The 
following theorem provides the proof that the partial schedules may be constructed by semi-active timetabling. Semi-active timetabling (French 1982) means that each activity is started as soon as it can within the precedence and resource constraints.

THEOREM 1. In order to solve the GRCPSP it is sufficient to construct the partial schedules by semi-active timetabling.

PROOF. See Appendix.

\subsection{Dominance rules}

Three dominance rules are used to prune the search tree. A first dominance rule is related to the construction of the delaying set $D(p)$ at level $p$ of the branching tree. We call a delaving alternative $D_{q} \varepsilon D(p)$ minimal if it does not contain other delaying alternatives $D_{v} \varepsilon D(p)$ as a subset.

THEOREM 2. In order to resolve a resource conflict it is sufficient to consider only minimal delaying alternatives.

PrOOF. See Appendix.

A second dominance rule is based on the definition of a cutset and will be referred to as the cutset dominance rule.

THEOREM 3. Consider a cutset $C_{m}$ at time $m$ which contains the same activities as a cutset $C_{k}$, which was previously saved during the search of another path in the search tree. If time $k$ was not greater than time $m$, if all activities in progress at time $\mathrm{k}$ did not finish later than the maximum of $\mathrm{m}$ and the finish time of the corresponding activities in $\mathrm{PS}_{\mathbf{m}}$ and if the earliest possible 
start time of every activity in $C_{k}$ is smaller than or equal to the earliest start time of the corresponding activity in $C_{m}$, then the current partial schedule $\mathbf{P S}_{m}$ is dominated.

PROOF. See Appendix.

A third and last dominance rule is called the left-shift dominance rule and considers the delaying alternatives that were used at the current level $\mathrm{p}$ and the previous level p - 1 of the solutions tree.

THEOREM 4. Consider the partial schedule $\mathrm{PS}_{\mathrm{m}}$ at level $\mathrm{p}$ of the solutions tree which starts activity $i$ at time $t$. If the delay of the delaying alternative that was selected at the previous level $p$ - 1 of the solutions tree forced this activity to become eligible at time $t$, and if this activity can be left-shifted without violating the precedence or resource constraints (because activities that were in progress were delayed by the current delaying alternative at level p), then the partial schedule PS $_{\mathbf{m}}$ is dominated.

PROOF. See Appendix.

These three dominance rules considerably reduce the number of schedules that have to be considered as well as the computation times involved. In the sequel of this section the branch-and-bound procedure is formally stated and demonstrated on a small problem example.

\subsection{The branch-and-bound procedure}

The detailed algorithmic steps of the branch-and-bound algorithm are described below. The save operation performed in step 2 below should be 
distinguished from the store operation performed in step 4. The save operation saves cutset information needed in order to apply the cutset dominance rule. The store operation saves information which is restored during backtracking.

\section{Step 1 : Initialisation.}

- Let $\mathrm{T}=9999$ be an upper bound on the project duration.

- Set the level of the branch-and-bound tree $p=0$.

- Initialize $\mathrm{m}=\mathrm{m}^{\prime}=0$.

- For all activities $\mathrm{i}$ for which a ready time $\mathrm{g}_{\mathrm{i}}$ is specified, put $\mathrm{FS}_{1 \mathrm{i}}=\max \left\{\mathrm{g}_{\mathrm{i}} ; \mathrm{FS}_{1 \mathrm{i}}\right\}$.

- For every activity $i$ compute the latest allowable start time $l_{i}$ based on its due date $h_{i}$ and the due dates of all direct or indirect successors of activity $i$.

- Compute FS $_{\mathrm{ij}}$ as indicated in Eq. [14].

- For every activity $i$ compute the remaining critical path length $q_{i}$ based on all finishstart relations.

- Schedule the dummy start activity : $\mathrm{f}_{1}=0, P S=\{1\}$ and $S=\{1\}$.

- Compute the lower bound at level $0: \operatorname{LB}(0)=\mathrm{q}_{1}$.

- Put all immediate successors of activity 1 , that have no other predecessors, in the cutset : $\mathrm{C}=\{\mathrm{x} \mid \mathrm{x}$ has activity 1 as a single predecessor $\}$ and set the early start times $\mathrm{s}_{\mathrm{X}}$ of the cutset activities $\mathrm{x}$ equal to $\mathrm{FS}^{\prime}{ }_{1 \mathrm{X}}$.

\section{Step 2 : Augmentation.}

- If the dummy end activity $n$ belongs to the partial schedule PS, the schedule is completed. Update the schedule length $T=f_{n}$. If $T$ equals $L B(0)$, then STOP (with the optimal solution), else decrease the branching level $p=p-1$ and go to step 6 (backtrack).

- Compute the next decision point $\mathrm{m}$ as the smallest early start time of all cutset activities $: \mathrm{m}=\min \left\{\mathrm{s}_{\mathrm{X}} \mid \mathrm{x} \in \mathrm{E}\right\}$.

- For all activities $\mathrm{j} \in \mathrm{S}$ for which $\mathrm{f}_{\mathrm{j}}<=\mathrm{m}$ update the set of activities in progress : $S=S-\{j\}$ 
- Check if the current cutset is dominated by a previously saved cutset. If it is dominated, go to step 6 (backtrack), else save the current cutset C with the corresponding early start times, the decision point $\mathrm{m}$ at which it is saved and the activities in progress as well as their finish times.

- Construct the eligible set : $E=\left\{x \in C \mid s_{X}=m\right\}$.

\section{Step 3 : Scheduling.}

- Temporarily put all eligible activities in progress : for all $i \varepsilon E$ set $f_{i}=m+d_{i}$, $\mathrm{PS}=\mathrm{PS}+\{\mathrm{i}\}$ and $\mathrm{S}=\mathrm{S}+\{\mathrm{i}\}$.

- Update the cutset : $C=C-E+\{x \mid x$ is an immediate successor of an activity i $\varepsilon E$ and all predecessors of $\mathrm{x}$ belong to PS $\}$ and set the early start times of these new cutset activities : $s_{x}=\max \left\{f_{y}+F S_{y x}^{\prime} \mid(y, x) \varepsilon H\right\}$.

- For each resource type $k$ check if $\sum r_{i k}<=a_{k m}$. If there is at least one resource i $\varepsilon S$

type $\mathrm{k}$ for which the sum of the resource requirements of all activities in progress exceeds the resource availability at time $\mathrm{m}$, we have a resource conflict : go to step 4 , else go to step 2 .

\section{Step 4 : Resource conflict.}

- Update the branch level of the search tree $: p=p+1$.

- Determine for each resource type $\mathrm{k}$ how many units have to be released in order to resolve the resource conflict : for each resource type $k$ compute $c_{k}=\sum r_{i k}-a_{k m}$.

$$
\text { i } \varepsilon S
$$

- Define the delaying set $D(p)=\left\{D_{q} \mid D_{q}\right.$ is a subset of $S, \quad \sum r_{i k}>=c_{k}$ for each

$$
\text { i } \in D_{q}
$$

resource type $\mathrm{k}$, all successors of an activity i $\varepsilon \mathrm{D}_{\mathrm{q}}$ that are in progress also belong to $\mathrm{D}_{\mathrm{q}}$ and $\mathrm{D}_{\mathrm{q}}$ does not contain another $\mathrm{D}_{\mathrm{v}} \varepsilon \mathrm{D}(\mathrm{p})$ as a subset $\}$.

- For every $D_{q} \varepsilon D(p)$ determine the minimum of the next change in the resource availability, the earliest finish time of all activities that remain in progress if $D_{q}$ is 
delayed and the earliest possible finish time of all unscheduled activities that have no predecessor in $\mathrm{D}_{\mathrm{q}}$. Assign this value to $\mathrm{w}_{\mathrm{q}}$.

- Compute the precedence-based lower bound $\mathrm{L}_{\mathrm{q}}$ for every delaying alternative $\mathrm{D}_{\mathrm{q}}$ as the sum of $\mathrm{w}_{\mathrm{q}}$ and the maximum of all remaining critical path lengths $\mathrm{q}_{\mathrm{i}}$ for each activity i $\varepsilon \mathrm{D}_{\mathrm{q}}$.

- Select the $D_{b} \varepsilon D(p)$ with the smallest $L_{b}$ (ties are broken arbitrarily) : the subscript $\mathrm{b}$ denotes the best delaying alternative left at level $\mathrm{p}$.

- Update the delaying set $: D(p)=D(p)-D_{b}$.

- Set $L B(p)=\max \left\{L B(p-1), L_{b}\right\}$. If $L B(p)>=T$, decrease the branching level $\mathrm{p}=\mathrm{p}-1$ and go to step 6 .

- Store the activity completion times $\mathrm{f}_{\mathrm{i}}$, the partial schedule PS, the set $\mathrm{S}$ of activities in progress, the set $C$ of cutset activities with their early start times $s_{X}$ and the decision points $\mathrm{m}$ and $\mathrm{m}$ '.

\section{Step 5 : Delaying.}

- Branch into a new node. Define DS as the set of all activities that started earlier than at time $m^{\prime}$ but must be delayed : $D S=\left\{i \varepsilon D_{b} \mid f_{i}-d_{i}<m^{\prime}\right\}$.

- Delay the delaying alternative $: P S=P S-D_{b}$ and $S=S-D_{b}$. Remove from PS all activities that are an immediate successor of one of the activities $i \varepsilon \mathrm{D}_{b}$ and that belong to the partial schedule PS.

- Update the cutset : $C=C+D_{b}-\left\{y \mid x \in D_{b}\right.$ and $\left.(x, y) \varepsilon H\right\}$.

- For all i $\varepsilon \mathrm{D}_{\mathrm{b}}$, if $\mathrm{i} \varepsilon \mathrm{C}$, update the early start times : $\mathrm{s}_{\mathrm{i}}=\mathrm{w}_{\mathrm{b}}$.

- If an activity i $\varepsilon D_{b}$ has been assigned an early start time $s_{i}$ that is larger than its latest allowable start time $l_{i}$, go to step 6 (backtrack).

- Update $m^{\prime}=m$.

- If DS is not empty, invoke the left-shift dominance rule as follows. If the inclusion of an activity $i$ in the delaying alternative, that was chosen at the previous level p - 1 of the solutions tree forced activity $i$ to become eligible at time m', if activity $i$ is started at time $\mathrm{m}^{\prime}$ and if delaying the activity set DS would allow activity $i$ to be 
left-shifted without causing a resource conflict, then this schedule is dominated : go to step 6 (backtrack).

- Go to step 2.

\section{Step 6 : Backtracking.}

- If the branching level $\mathrm{p}=0$, then STOP.

- If no delaying alternatives are left at this level (i.e., if $D(p)=\emptyset$ ), set $p=p-1$ and repeat step 6.

- Select the delaying alternative $\mathrm{D}_{b} \varepsilon \mathrm{D}(\mathrm{p})$ with the smallest lower bound $\mathrm{L}_{\mathrm{b}}$ left at this level (ties are broken arbitrarily) and update the delaying set $D(p)=D(p)-D_{b}$.

- Compute the lower bound $\mathrm{LB}(\mathrm{p})=\max \left\{\mathrm{LB}(\mathrm{p}-1), \mathrm{L}_{\mathrm{b}}\right\}$. If $\mathrm{LB}(\mathrm{p})>=\mathrm{T}$, decrease the branching level : $\mathrm{p}=\mathrm{p}-1$ and repeat step 6 .

- Restore the activity completion times $f_{i}$, the partial schedule PS, the set $S$ of activities in progress, the set $C$ of cutset activities with their early start times $s_{X}$ and the decision points $\mathrm{m}$ and $\mathrm{m}$ '. Go to step 5 .

\subsection{Numerical example}

In this section a small example will be solved in order to demonstrate the different steps of the branch-and-bound procedure that was described in Section 2.6. The example is a multi-project scheduling problem and is represented in Figure 2. The numbers inside the nodes denote the activity numbers, the ones above each node signify the activity durations and the numbers below each node denote the resource requirements for the two different resource types. The type of precedence relation and the associated time lag are indicated on each arc of the network.

Insert Figure 2 
In Figure 2 it can be seen that 3 different projects have to be scheduled. A first project consists of activities 2 to 6 and has an assumed ready time of 5 and a due date of 20 (the ready time is defined for activity $2: \mathrm{g}_{2}=5$, while the due date is defined for activity $6: h_{6}=20$ ). A second project, consisting of activities 7 to 10 , has a ready time of 0 and a due date of 15 , while a third project consists of activities 11 to 13 and has a ready time of 0 and a due date of 25 . It is assumed that the resource availabilities are varying over time. For ease of reference these values are indicated in Table I.

Insert Table I

In the first step of the branch-and-bound procedure all ready times and precedence relations are converted into finish-start precedence relations $\mathrm{FS}_{\mathrm{ij}}{ }_{\mathrm{j}}$. For ease of reference these values are shown in Figure 3. Observe the extra arc that is added between activities 2 and 4 as these activities can be partially overlapped $\left(\mathrm{FS}_{24}^{\prime}=-1\right)$. As mentioned before, the extra arc is added in order to simplify the task of generating delaying alternatives.

Insert Figure 3

The different steps of the branch-and-bound procedure will now be demonstrated on this numerical example :

Step $1:$ Let $\mathrm{T}=9999 ; \mathrm{m}=\mathrm{m}^{\prime}=\mathrm{p}=0$. Convert all ready times and precedence relations (see Figure 3). Compute the latest allowable start times : $1_{14}=9999$; $l_{13}=21 ; l_{12}=18 ; l_{11}=12 ; l_{10}=9 ; l_{9}=5 ; l_{8}=6 ; l_{7}=3 ; l_{6}=18 ; 1_{5}=11$; $l_{4}=13 ; l_{3}=12 ; l_{2}=5 ; 1_{1}=0$. Compute the remaining critical path length : 
$\mathrm{q}_{14}=0 ; \mathrm{q}_{13}=4 ; \mathrm{q}_{12}=7 ; \mathrm{q}_{11}=13 ; \mathrm{q}_{10}=6 ; \mathrm{q}_{9}=10 ; \mathrm{q}_{8}=9 ; \mathrm{q}_{7}=12 ; \mathrm{q}_{6}=2$; $\mathrm{q}_{5}=9 ; \mathrm{q}_{4}=7 ; \mathrm{q}_{3}=8 ; \mathrm{q}_{2}=15 ; \mathrm{q}_{1}=20$. Schedule the dummy start activity 1 : $\mathrm{f}_{1}=0 ; \mathrm{PS}=\{1\} ; \mathrm{S}=\{1\}$. The lower bound at level 0 of the search tree is computed as $\operatorname{LB}(0)=20$. Construct the cutset $C=\{2,7,11\}$ and compute the early start times of all cutset activities : $s_{2}=5 ; s_{7}=s_{11}=0$.

Step 2 : Update $\mathrm{m}=0$ and $\mathrm{S}=\emptyset$. C is not dominated : save the cutset. Construct the eligible set $E=\{7,11\}$.

Step 3 : Temporarily put all eligible activities in progress : $P S=\{1,7,11\} ; S=\{7$, $11\} ; \mathrm{f}_{7}=2 ; \mathrm{f}_{11}=4$. Update the cutset $\mathrm{C}=\{2,8,9,12\}$ and assign early start times to the activities that are added to the cutset $s_{8}=3 ; s_{9}=2 ; s_{12}=6$. Since 3 $<=6$ and $3<=5$, no resource conflict occurs.

Step $2: m=2 ; S=\{11\} ; C$ is not dominated : save; $E=\{9\}$.

Step $3: P S=\{1,7,9,11\} ; S=\{9,11\} ; f_{9}=7 . C=\{2,8,12\} .1<=6$ and $4<=5:$ no resource conflict.

Step $2: m=3 ; S=\{9,11\} ; C$ not dominated : save; $E=\{8\}$.

Step $3: P S=\{1,7,8,9,11\} ; S=\{8,9,11\} ; f_{8}=7 . C=\{2,10,12\} ; s_{10}=6.4<=6$ and $5<=5$ : no resource conflict.

Step $2: m=5 ; S=\{8,9\} ; C$ not dominated : save; $E=\{2\}$.

Step $3: P S=\{1,2,7,8,9,11\} ; S=\{2,8,9\} ; f_{2}=9 . C=\{3,5,10,12\} ; s_{3}=7$; $s_{5}=11.5<=6$ and $4<=5:$ no resource conflict.

Step $2: m=6 ; S=\{2,8,9\} ; C$ not dominated : save; $E=\{10,12\}$.

Step $3: P S=\{1,2,7,8,9,10,11,12\} ; S=\{2,8,9,10,12\} ; f_{10}=12 ; f_{12}=11$. $C=\{3,5,13\} ; s_{13}=9.8>6$ and $8>5:$ a resource conflict occurs.

Step $4:$ Update the level of the search tree $p=1$. In order to resolve the current resource conflict, 2 units of resource type 1 and 3 units of resource type 2 must be released : $c_{1}=2 ; c_{2}=3$. Define the delaying set $D(1)=\{\{10\}\}$.

For the single delaying alternative $D_{1}=\{10\}$, the delaying point is computed as $w_{1}=7$, which is equal to the minimum of the next change in the resource availability (7), the earliest finish time of all activities that 
remain in progress if $D_{1}$ is delayed (activities 8 and 9 finish at time 7) and the earliest possible finish time of all unscheduled activities that have no predecessor in $D_{1}$ (activity 3 could finish at time 10). Compute the precedence-based lower bound $\mathrm{L}_{1}=7+6=13$.

Select $D_{1}: D(1)=\emptyset ; \operatorname{LB}(1)=\max \{20,13\}=20<\mathrm{T}$; store the present situation.

Step $5:$ Branch into node 1 of the solutions tree (see Figure 4). Compute DS $=\emptyset$ and delay the delaying alternative : $P S=\{1,2,7,8,9,11,12\}$ and $S=\{2,8,9,12\}$. Update the cutset $C=\{3,5,10,13\}$, the early start time of the delayed activity : $\mathrm{s}_{10}=7<=1_{10}$ and $\mathrm{m}^{\prime}=6$.

Step 2: $m=7 ; S=\{2,12\} ; C$ not dominated : save; $E=\{3,10\}$.

Step $3: P S=\{1,2,3,7,8,9,10,11,12\} ; S=\{2,3,10,12\} ; f_{3}=10 ; f_{10}=13$.

$\mathrm{C}=\{4,5,13\} ; \mathrm{s}_{4}=8.6<=7$, but $7>5:$ a resource conflict occurs.

Step $4: p=2 ; c_{1}=-1$ and $c_{2}=2: D(2)=\{\{3\},\{10\}\}$.

$$
\begin{aligned}
& D_{2}=\{3\} ; w_{2}=9 ; L_{2}=17 \\
& D_{3}=\{10\} ; w_{3}=9 ; L_{3}=15
\end{aligned}
$$

Select $\mathrm{D}_{3}: \mathrm{D}(2)=\{\{3\}\} ; \mathrm{LB}(2)=20<\mathrm{T}$; store.

Step 5 : Branch into node 2 of the solutions tree (see Figure 4). DS $=\varnothing ; P=\{1,2,3$,

$7,8,9,11,12\} ; S=\{2,3,12\} . C=\{4,5,10,13\} ; s_{10}=9<=1_{10} ; m^{\prime}=7$.

Step $2: m=8 ; S=\{2,3,12\} ; C$ not dominated : save; $E=\{4\}$.

Step $3: P S=\{1,2,3,4,7,8,9,11,12\} ; S=\{2,3,4,12\} ; f_{4}=13 . C=\{5,10,13\}$.

$5<=7$ and $5<=5$ : no resource conflict.

Step 2: $m=9 ; S=\{3,4,12\} ; C$ not dominated : save; $E=\{10,13\}$.

Step $3: P S=\{1,2,3,4,7,8,9,10,11,12,13\} ; S=\{3,4,10,12,13\} ; f_{10}=15$;

$\mathrm{f}_{13}=13 . \mathrm{C}=\{5\} .6<=7$, but $9>5:$ a resource conflict occurs.

Step $4: p=3 ; c_{1}=-1$ and $c_{2}=4: D(3)=\{\{4,10\},\{10,13\},\{3,4,13\},\{4,12,13\}\}$.

$$
\begin{aligned}
& D_{4}=\{4,10\} ; w_{4}=10 ; L_{4}=17 \\
& D_{5}=\{10,13\} ; w_{5}=10 ; L_{5}=16 \\
& D_{6}=\{3,4,13\} ; w_{6}=11 ; L_{6}=19 \\
& D_{7}=\{4,12,13\} ; w_{7}=10 ; L_{7}=17
\end{aligned}
$$


Select $D_{5}: D(3)=\{\{4,10\},\{3,4,13\},\{4,12,13\}\} ; \operatorname{LB}(3)=20<\mathrm{T}$; store.

Step 5 : Branch into node 3 of the branch-and-bound tree. DS $=\emptyset ; P S=\{1,2,3,4,7$, $8,9,11,12\} ; S=\{3,4,12\} . C=\{5,10,13\} ; s_{10}=10>1_{10}:$ backtrack.

Step 6 : Select $D_{4}$ at level $3: D(3)=\{\{3,4,13\},\{4,12,13\}\} ; \mathrm{LB}(3)=20<\mathrm{T}$; restore the situation.

Step $5:$ Branch into node 4 of the search tree. DS $=\emptyset ; P S=\{1,2,3,7,8,9,11,12$, $13\} ; S=\{3,12,13\} . C=\{4,5,10\} ; s_{4}=10<=1_{4} ; s_{10}=10>1_{10}$ : backtrack.

Step $6:$ Select $\mathrm{D}_{7}$ at level $3: \mathrm{D}(3)=\{\{3,4,13\}\} ; \mathrm{LB}(3)=20<\mathrm{T}$; restore.

Step 5 : Branch into node 5 of the solutions tree. $D S=\{12\} ; P S=\{1,2,3,7,8,9$, $10,11\} ; S=\{3,10\} . C=\{4,5,12\} ; s_{4}=10<=1_{4} ; s_{12}=10<=112 ; m^{\prime}=9$. No left-shift dominance.

Step 2: $\mathrm{m}=10 ; \mathrm{S}=\{10\} ; \mathrm{C}$ not dominated : save; $\mathrm{E}=\{4,12\}$.

Step $3: P S=\{1,2,3,4,7,8,9,10,11,12\} ; S=\{4,10,12\} ; f_{4}=15 ; f_{12}=15$.

$\mathrm{C}=\{5,13\} ; \mathrm{s}_{13}=13.4<=7$ and $5<=5:$ no resource conflict.

Step $2: m=11 ; S=\{4,10,12\} ; C$ not dominated : save; $E=\{5\}$.

Step $3: P S=\{1,2,3,4,5,7,8,9,10,11,12\} ; S=\{4,5,10,12\} ; f_{5}=15 . C=\{6$,

$13\} ; s_{6}=18.7<=7$, but $6>5:$ resource conflict.

Step $4: p=4 ; c_{1}=0$ and $c_{2}=1: D(4)=\{\{4\},\{5\},\{10\},\{12\}\}$.

$$
\begin{aligned}
& D_{8}=\{4\} ; w_{8}=12 ; L_{8}=19 \\
& D_{9}=\{5\} ; w_{9}=12 ; L_{9}=21 \\
& D_{10}=\{10\} ; w_{10}=12 ; L_{10}=18 \\
& D_{11}=\{12\} ; w_{11}=12 ; L_{11}=19
\end{aligned}
$$

Select $D_{10}: D(4)=\{\{4\},\{5\},\{12\}\} ; \operatorname{LB}(4)=20<T$; store.

Step 5 : Branch into node 6 of the branch-and-bound tree. DS $=\{10\} ; P S=\{1,2,3$, $4,5,7,8,9,11,12\} ; S=\{4,5,12\} . C=\{6,10,13\} ; s_{10}=12>1_{10}:$ backtrack. Step 6 : Select $\mathrm{D}_{8}$ at level $4: \mathrm{D}(4)=\{\{5\},\{12\}\} ; \mathrm{LB}(4)=20<\mathrm{T}$; restore.

Step $5:$ Branch into node 7 of the branch-and-bound tree. $D S=\emptyset ; P S=\{1,2,3,5,7$, $8,9,10,11,12\} ; S=\{5,10,12\} . C=\{4,13\} ; s_{4}=12<=14 ; m^{\prime}=11$.

Step $2: m=12 ; S=\{5,10,12\} ; C$ not dominated : save; $E=\{4\}$. 
Step $3: P S=\{1,2,3,4,5,7,8,9,10,11,12\} ; S=\{4,5,10,12\} ; f_{4}=17 . C=\{6$, $13\} ; s_{6}=18.7<=7$ and $6<=6$; no resource conflict.

Step $2: m=13 ; S=\{4,5,10,12\} ; C$ not dominated : save; $E=\{13\}$.

Step $3: P S=\{1,2,3,4,5,7,8,9,10,11,12,13\} ; S=\{4,5,10,12,13\} ; f_{13}=17$.

$\mathrm{C}=\{6\} .8>7$ and $8>6$ : resource conflict.

Step $4: p=5 ; c_{1}=1$ and $c_{2}=2: D(5)=\{\{10\},\{13\},\{4,5\}\}$.

$$
\begin{aligned}
& \mathrm{D}_{12}=\{10\} ; \mathrm{w}_{12}=15 ; \mathrm{L}_{12}=21 \\
& \mathrm{D}_{13}=\{13\} ; \mathrm{w}_{13}=15 ; \mathrm{L}_{13}=19 \\
& \mathrm{D}_{14}=\{4,5\} ; \mathrm{w}_{14}=15 ; \mathrm{L}_{14}=22
\end{aligned}
$$

Select $\mathrm{D}_{13}: \mathrm{D}(5)=\{\{10\},\{4,5\}\} ; \mathrm{LB}(5)=20<\mathrm{T}$; store.

Step $5:$ Branch into node 8 of the solutions tree. DS $=\emptyset ; P S=\{1,2,3,4,5,7,8,9$, $10,11,12\} ; S=\{4,5,10,12\} . C=\{6,13\} ; s_{13}=15<=l_{13} ; m^{\prime}=13$.

Step $2: m=15 ; S=\{4\} ; C$ not dominated : save; $E=\{13\}$.

Step $3: P S=\{1,2,3,4,5,7,8,9,10,11,12,13\} ; S=\{4,13\} ; f_{13}=19 . C=\{6\}$.

$2<=7$ and $3<=6$ : no resource conflict.

Step $2: m=18 ; S=\{13\} ; C$ not dominated : save; $E=\{6\}$.

Step $3: P S=\{1,2,3,4,5,6,7,8,9,10,11,12,13\} ; S=\{6,13\} ; f_{6}=20 . C=\{14\}$;

$s_{14}=20.4<=5$ and $3<=5:$ no resource conflict.

Step 2: $\mathrm{m}=20 ; \mathrm{S}=\emptyset ; \mathrm{C}$ not dominated : save; $\mathrm{E}=\{14\}$.

Step $3: P S=\{1,2,3,4,5,6,7,8,9,10,11,12,13,14\} ; S=\{14\} ; f_{14}=20 . C=\emptyset$.

$0<=5$ and $0<=5:$ no resource conflict.

Step 2 : Activity 14 is scheduled : $\mathrm{T}=20=\mathrm{LB}(0)$ : stop with optimal solution.

The branch-and-bound tree for this small problem is represented in Figure 4. It should be noticed that no cutset dominance occurs for this problem as most of the nodes that were visited lie on a single path in the solutions tree. In general, increased benefit results from dominance rules and lower bounds whenever the size of the problem increases. One should also observe that at level 1 of the solutions tree there is only one possible delaying alternative. In the absence of precedence diagramming 
constraints, the delaying sets at every level of the solutions tree would contain at least two delaying alternatives.

\section{Insert Figure 4}

The optimal solution that was found is shown in Figure 5. Figure 5a exhibits the resource profile for the first resource type, while Figure $5 \mathrm{~b}$ displays the resource profile for the second resource type.

\section{Insert Figure 5}

The computational results of the branch-and-bound procedure will be presented in the next section. 


\section{COMPUTATIONAL EXPERIENCE}

In this section, two problem sets will be used to gain computational experience with the branch-and-bound solution method that was described in the previous section. The first set has been constructed by Simpson (1991) and was based on the Patterson problem set which is generally accepted as the standard problem set for the RCPSP. The modifications to that set have already been described in Section 1 of this paper. These problems are used to test the influence of the introduction of variable resource availability on the efficiency of the solution methodology. The second problem set is new and is based on problem 72, which is experienced by the procedure of Demeulemeester and Herroelen (1991) to be the most difficult problem in the Patterson problem set. Through the addition and removal of constraints within the scope of the GRCPSP, an indication is obtained of the influence of these additional constraints on the computation time required.

The computational experience with the problem set of Simpson is described in Table II. It should be realized that Simpson's solution procedures were run on a mainframe computer, whereas our procedure was tested on a personal computer running under DOS. While the serial and parallel procedures of Simpson were able to solve 97 , respectively 98 problems out of 110 within a time limit of $600 \mathrm{CPU}$ seconds, our procedure solved all 110 problems in a very short computation time (all computation times were less than 15 seconds). There also exists a large difference in the average computation times between the three methods : while the procedures of Simpson used an average of 100.85 to solve 97 problems and 96.63 seconds to solve 98 problems optimally, our procedure required an average computation time of 1.2326 seconds to solve all problems to optimality. The standard deviation for all three procedures typically amounts to twice the average computation time. A comparison with the results obtained by the procedure of Demeulemeester and 
Herroelen (1991) on the Patterson problem set with constant resource availabilities, shows that the required computation time increases by a factor of about six.

Insert Table II

The results in Table II clearly demonstrate the efficiency of the branch-andbound procedure when variable resource availabilities are introduced. A small experiment has been conducted in order to test the computational impact of the addition of precedence diagramming type of precedence relations, ready times and due dates. The problem set is based on variations of Patterson's difficult problem 72. This problem involves the scheduling of 27 activities subject to constant availability constraints on three resource types. The results for this problem set are presented in Table III.

Insert Table 3

The standard problem referred to in row 1 of Table III is constructed as follows. Problem 72 of the Patterson problem set is copied into the correct format for the GRCPSP. No ready times or due dates were introduced, but 10 resource intervals were specified, one occurring every 5 time units. The resource availability for each of the three resource types during one of these resource intervals was randomly chosen from the interval $[6,9]$. Precedence diagramming constraints were introduced as follows. For each pair of activities $(i, j)$ in the original problem, the corresponding finish-start relationship with a time lag of zero is changed into a finish-start relation with a time lag $\mathrm{FS}_{\mathrm{ij}}$. This time lag was randomly chosen from the uniformly distributed interval $\left[-\mathrm{d}_{\mathrm{i}}, \mathrm{d}_{\mathrm{i}}\right]$. As indicated in Table III, this problem could be solved to optimality in 1.59 seconds. The addition of due dates for activities 18 and 22 (see row 
2 in Table III) results in a much faster solution. This effect is quite normal as the introduction of due dates restricts the feasible solution space and therefore also the time needed to search this solution space for an optimal solution. The introduction of two ready times (row 3 in Table III) or an increase in the resource availability in one resource interval (row 4 in Table III) does not have much impact upon the computation time. Allowing more overlapping between different activities (three of the positive $F S_{i j}$-values were made negative), a very significant increase in the required computation time is observed. This result was to be expected : increased overlapping of activities increases the number of resource conflicts, which is directly related to the number of levels in the branch-and-bound tree and, hence, the size of the solutions tree. The process of changing due dates, ready times, resource availability and time lags of the precedence relations is then repeated once more, leading to similar observations as shown in the bottom five rows in Table III.

The computational experience reported in this section allows for a number of conclusions. The variable resource availability problem can be solved in a computation time, which is about six times higher than the time needed by the exact procedure of Demeulemeester and Herroelen (1991), the current best solution procedure for solving the RCPSP. Moderate changes in the ready times or in the resource availabilities do not have a significant impact on the computation times. The introduction of due dates decreases the solution time enormously. Allowing activity overlaps (negative $\mathrm{FS}_{\mathrm{ij}}$-values) causes a strong increase in the computation times required. 


\section{CONCLUSIONS}

In this paper a new depth-first branch-and-bound algorithm was described for the generalized resource-constrained project scheduling problem (GRCPSP) which involves the scheduling of a project to minimize its total duration, subject to precedence constraints of the precedence diagramming type, ready times, due dates and variable resource availability constraints. Computational experience gained with the algorithm on a personal computer was very promising. On Simpson's modified 110 Patterson test problems with variable resource availabilities, an optimal solution could be found in an average CPU time of 1.2329 seconds and a standard deviation of 2.3133 seconds on an IBM PS/2 Model 70 A21 with a $25 \mathrm{MHz}$ processor and a coprocessor. As such it seems to be more efficient and effective than the current best exact solution procedure reported in the literature. Compared to computational experience gained with the algorithm on the classical resource-constrained project scheduling problem (RCPSP), computation times seem to increase by a factor of about six.

Experience gained with modified versions of one of the most difficult Patterson problems, seems to indicate that moderate changes in ready times or resource availabilities do not have significant impact on the computation time. The introduction of activity due dates, however, has a strong beneficial impact on the required computational effort, while the introduction of activity overlaps (negative finish-start time lags) leads to a considerable increase in the CPU time required.

It would be tempting to consider possible extensions of the branch-and-bound algorithm to even more general problem types, namely the case of variable resource requirements and the case of generalized precedence constraints (Elmaghraby and Kamburowski 1989). In the latter case, maxima are imposed on the precedence lag, indicating that the start or finish of a successor should not occur more than a certain 
period later than the start or finish of its corresponding predecessor. In both cases, however, the use of semi-active timetabling no longer guarantees the optimal solution. This fact forces a branch-and-bound procedure to make scheduling decisions at every discrete time instant (see e.g. the procedure of Davis and Heidorn 1971), with the result that the solution tree grows unwieldy even for moderately sized projects. 


\begin{abstract}
APPENDIX
Proof of Theorem 1 (based on French 1982, pages 27 - 28)

Consider an optimal schedule which has not been constructed by semi-active timetabling. Then there is at least one activity which could be started earlier. Of all such activities choose one with the earliest finish time (ties are broken arbitrarily). Retimetable this activity to start as early as possible without violating any precedence or resource constraints. In this new schedule no finish time has increased and thus the schedule length remains unchanged.
\end{abstract}

Repeat this process of retimetabling activities, which could have started earlier, until there are no such activities left. Note that, because we always pick an activity which has the earliest finish time, no activity can be retimetabled more than once. There are a finite number of activities so this retimetabling process must terminate. The final schedule is the result of semi-active timetabling, since no activity could be started earlier. Moreover, since the schedule length did not increase at any stage, the final schedule is at least as good as the original. Hence, there exists an optimal schedule that can be found by semi-active timetabling.

\title{
Proof of Theorem 2
}

Let $\left(z_{0}, \ldots, z_{p}, \ldots, z_{k}\right)$ be the chain of nodes in the solutions tree that is leading to an optimal schedule $G$. With each such node $z_{p}$ at level $p$ of the solutions tree corresponds a delaying alternative $\mathrm{D}_{\mathrm{z}_{\mathrm{p}}}$, a delaying point $\mathrm{w}_{\mathrm{z}_{\mathrm{p}}}$ and a set of constraints $\Omega_{z_{p}}$. For node $z_{0}$ the set $\Omega_{z_{0}}$ equals the original precedence constraints, the ready times and due dates as well as the resource constraints. For all other nodes $z_{p}$ the set $\Omega_{z_{p}}$ is obtained by adding to $\Omega_{z_{p-1}}$ the additional constraints that all activities in $D_{z_{p}}$ 
cannot start before the corresponding delaying point $\mathrm{w}_{\mathrm{z}_{\mathrm{p}}}$. Let $\mathrm{f}_{\mathrm{j}}{ }^{*}$ denote the finish time of activity $\mathrm{j}$ in the optimal schedule $\mathrm{G}$.

Let node $z_{q}$ be the first node in the chain for which the delaying alternative $D_{z_{q}}$ is non-minimal. If no such $\mathrm{z}_{\mathrm{q}}$ exists, we are done.

Otherwise, let time $\mathrm{m}$ be the decision point at which the resource conflict occurred. Finish times $f_{j}$ are associated with all scheduled activities (i.e., $j \varepsilon\left(P S_{m}-D_{z_{q}}\right)$ ) as well as early start times $s_{1}$ for all unscheduled activities (i.e., i $\varepsilon\left(\mathrm{NS}_{\mathrm{m}}+\mathrm{D}_{\mathrm{z}_{\mathrm{q}}}\right)$ ). For each activity i $\varepsilon D_{z_{q}}$ we have $s_{i}=w_{z_{q}}$ and for every other unscheduled activity the early start time is dependent upon the precedence relations. By definition of a minimal delaying alternative, there exists at least one activity $\mathrm{x}$ that can be removed from $\mathrm{D}_{\mathrm{z}_{\mathrm{q}}}: \mathrm{D}_{\mathrm{v}_{\mathrm{q}}}=\mathrm{D}_{\mathrm{z}_{\mathrm{q}}}-\{\mathrm{x}\}$ such that $\mathrm{D}_{\mathrm{v}_{\mathrm{q}}}$ is a valid delaying alternative, occurring at node $v_{q}$ at level $q$ of the search tree. Now two possibilities have to be considered:

(a) In case neither activity $\mathrm{x}$ nor any of the successors of activity $\mathrm{x}$ without direct or indirect predecessors in $\left(\mathrm{NS}_{\mathrm{m}}+\mathrm{D}_{\mathrm{v}_{\mathrm{q}}}\right)$ could finish before the delaying point $w_{z_{q}}, w_{z_{q}}$ would also be the delaying point for the delaying alternative $D_{v_{q}}$ (i.e., $\left.\mathrm{w}_{\mathrm{v}_{\mathrm{q}}}=\mathrm{w}_{\mathrm{z}_{\mathrm{q}}}\right)$. As $\mathrm{D}_{\mathrm{v}_{\mathrm{q}}}=\mathrm{D}_{\mathrm{z}_{\mathrm{q}}}-\{\mathrm{x}\}$, we have that the added constraints at node $\mathrm{v}_{\mathrm{q}}$ are a subset of those added at node $\mathrm{z}_{\mathrm{q}}$ and hence $\Omega_{\mathrm{v}_{\mathrm{q}}}$ is a subset of $\Omega_{\mathrm{z}_{\mathrm{q}}}$. As the schedule $\mathrm{G}$ is feasible to $\Omega_{\mathrm{z}_{\mathrm{q}}}, \mathrm{G}$ is also feasible to $\Omega_{\mathrm{v}_{\mathrm{q}}}$ and therefore can be found by continuing the branching process from $v_{q}$. Hence, node $z_{q}$ can be fathomed.

(b) If either activity $x$ or any of the successors of activity $x$ without direct or indirect predecessors in $\left(\mathrm{NS}_{\mathrm{m}}+\mathrm{D}_{\mathrm{v}_{\mathrm{q}}}\right)$ could finish before the delaying point $\mathrm{w}_{\mathrm{z}_{\mathrm{q}}}, \mathrm{w}_{\mathrm{v}_{\mathrm{q}}}$ would equal the smallest finish time of one of these activities and thus $\mathrm{w}_{\mathrm{v}_{\mathrm{q}}}<\mathrm{w}_{\mathrm{z}_{\mathrm{q}}}$. As $\mathrm{D}_{\mathrm{v}_{\mathrm{q}}}=\mathrm{D}_{\mathrm{z}_{\mathrm{q}}}-\{\mathrm{x}\}$ and $\mathrm{w}_{\mathrm{v}_{\mathrm{q}}}<\mathrm{w}_{\mathrm{z}_{\mathrm{q}}}$, we have that the added constraints at node $\mathrm{v}_{\mathrm{q}}$ are less strict than the constraints that were added at node $\mathrm{z}_{\mathrm{q}}$ and therefore $\Omega_{\mathrm{v}_{\mathrm{q}}}$ is less restrictive than $\Omega_{\mathrm{z}_{\mathrm{q}}}$. Thus the optimal schedule G, 
which by assumption is feasible to $\Omega_{\mathrm{z}_{\mathrm{q}}}$, is also feasible to $\Omega_{\mathrm{v}_{\mathrm{q}}}$ and therefore can be found by continuing the branching process from $\mathrm{v}_{\mathrm{q}}$. Hence, node $\mathrm{z}_{\mathrm{q}}$ can be fathomed.

Now we have proven that an optimal solution can be found if branching takes place from a delaying alternative that has one activity less than the first non-minimal delaying alternative, encountered at node $\mathrm{z}_{\mathrm{q}}$ of the solutions tree. The process of removing an activity from this non-minimal delaying alternative can be continued until a minimal delaying alternative $\mathrm{D}_{\mathrm{b}_{\mathrm{q}}}$ is obtained at node $\mathrm{b}_{\mathrm{q}}$. If branching continues from $b_{\mathrm{q}}$, a new optimal schedule can be found along the chain $\left(\mathrm{z}_{0}, \ldots, \mathrm{z}_{\mathrm{q}-1}\right.$, $\mathrm{b}_{\mathrm{q}}, \mathrm{b}_{\mathrm{q}+1}, \ldots, \mathrm{b}_{\mathrm{k}^{\prime}}$. Along this chain all delaying alternatives at nodes $\mathrm{z}_{1}, \ldots, \mathrm{b}_{\mathrm{q}}$ are minimal by construction, while the delaying alternatives at nodes $b_{q+1}, \ldots, b_{k^{\prime}}$ could be non-minimal. The procedure of removing activities from a non-minimal delaying alternative until a minimal delaying alternative is obtained can again be performed at that level where the first non-minimal delaying alternative occurred along the new chain. This action can then be repeated until all delaying alternatives are minimal. Hence, it is proven that optimal schedules can be obtained by only considering minimal delaying alternatives.

\section{Proof of Theorem 3}

Let $G$ be an optimal schedule with finish times $\mathrm{f}_{\mathrm{i}}{ }^{*}$ generated by completing a partial schedule $\mathrm{PS}_{\mathrm{m}}$ for which the cutset $\mathrm{C}_{\mathrm{m}}$ satisfies the hypotheses of the theorem. Then there exists a cutset $C_{k}$ which was previously generated on a different path in the search tree and which corresponds to a partial schedule $\mathrm{PS}_{\mathrm{k}}=\mathrm{PS}_{\mathrm{m}}$. Moreover, $\mathrm{k}<=\mathrm{m}$ and for all $\mathrm{j} \varepsilon \mathrm{PS}_{\mathrm{k}}$ we have $\mathrm{f}_{\mathrm{jk}}<=\max \left\{\mathrm{m}, \mathrm{f}_{\mathrm{jm}}\right\}$ where $\mathrm{f}_{\mathrm{jk}}$ denotes the finish time of activity $j$ in $P S_{k}$ and $f_{j m}$ denotes the finish time of activity $j$ in $P S_{m}$. By assumption, we also have for all i $\varepsilon C_{k}=C_{m}$ that $s_{i k}<=s_{i m}$ where $s_{i k}$ denotes the early start time of activity $i$ in $C_{k}$ and $s_{i m}$ denotes the early start time of activity $i$ in 
$\mathrm{C}_{\mathrm{m}}$. As $\mathrm{G}$ is generated by completing $\mathrm{PS}_{\mathrm{m}}$ it holds for all activities $\mathrm{j} \varepsilon \mathrm{PS}_{\mathrm{m}}$ that $\mathrm{f}_{\mathrm{jm}}<=\mathrm{f}_{\mathrm{j}}^{*}$.

Let $\mathrm{J}$ denote the set of activities $j$ for which $f_{j}^{*}-d_{j}>m$. Construct a new schedule $G^{\prime}$ as follows : for all activities $j \varepsilon J$ set $f_{j}^{\prime}=f_{j}{ }^{*}$ and for all activities $i \varepsilon(A-J)$ set $\mathrm{f}_{\mathbf{i}} \mathbf{f}_{\mathrm{ik}} \cdot \mathrm{G}^{\prime}$ is a feasible schedule : no precedence relation is violated as, by hypothesis, for all predecessors $i$ of activities $j \varepsilon C_{m}$ it holds that $f_{i}=f_{i k}<=\max$ $\left\{\mathrm{m}, \mathrm{f}_{\mathrm{im}}\right\}<=\max \left\{\mathrm{m}, \mathrm{f}_{\mathrm{i}}^{*}\right\}$ and as for all cutset activities $\mathrm{j} \varepsilon \mathrm{C}_{\mathrm{m}}$ we have that $\mathrm{s}_{\mathrm{jk}}<=\mathrm{s}_{\mathrm{jm}}<=\mathrm{f}_{\mathrm{j}}{ }^{*}-\mathrm{d}_{\mathrm{j}}$. In addition no resource constraint is violated as $P S_{\mathrm{k}}$ and $\mathrm{G}$ were feasible and because for all activities $\mathrm{j} \varepsilon \mathrm{PS}_{\mathrm{k}}$, it holds that $\mathrm{f}_{\mathrm{jk}}<=\max \left\{\mathrm{m}, \mathrm{f}_{\mathrm{jm}}\right\}$ $<=\max \left\{\mathrm{m}_{,} \mathrm{f}_{\mathrm{j}}^{*}\right\}$ while all activities $\mathrm{i} \varepsilon \mathrm{J}$ are scheduled in $\mathrm{G}^{\prime}$ after both $\mathrm{m}$ and the maximal value of $f_{j}{ }^{*}+F S_{j i}$ for any of its predecessors $j . G^{\prime}$ has the same schedule length as $G$ and thus $G^{\prime}$, which could be obtained by branching from the node at which $\mathrm{PS}_{\mathrm{k}}$ was constructed, is also optimal. Therefore $\mathrm{PS}_{\mathrm{m}}$ is dominated.

\section{Proof of Theorem 4}

Assume a branching level $\mathrm{p}$ at which the assumptions of the theorem are satisfied. Then we have the following situation. At time $t^{\prime}<t$ the delaying alternative $D_{z_{p-1}}=$ \{i $+X$ (with $X$ an arbitrary subset of the activities in progress at time $t$, except activity i) was delayed until the delaying point $\mathrm{w}_{\mathrm{z}-1}=\mathrm{t}$. At time $\mathrm{t}^{\prime \prime}>=\mathrm{t}$ the delaying alternative $D_{z_{p}}=J+Y$ (with $J$ a set of activities that were in progress at time $t^{\prime}$ and $Y$ an arbitrary subset of the activities in progress at time $t^{\prime \prime}$, except $J$ ) is delayed until the delaying point $\mathrm{w}_{\mathrm{z}}>\mathrm{t}=\mathrm{w}_{\mathrm{z}-1} \cdot \mathrm{D}_{\mathrm{z}-1}^{\prime}=\mathrm{J}+\mathrm{X}$ is a valid (not necessarily minimal) delaying alternative at time $t^{\prime}$ and for this delaying alternative $w_{z_{p}-1}^{\prime}<=w_{z_{p}-1}$. The nodes $z_{p-1}$ and $z_{p-1}^{\prime}$ are descendants from the same node $z_{p-2}$ with the corresponding set of solutions $\Omega_{\mathrm{z}_{\mathrm{p}-2}}$. In node $\mathrm{z}_{\mathrm{p}-1}^{\prime}$ all solutions are deleted where the activities in J $+\mathrm{X}$ start earlier than at time instant $\mathrm{w}_{\mathrm{z}-1}^{\prime}$. At node $\mathrm{z}_{\mathrm{p}-1}$, all solutions are deleted where activities in $X$ start earlier than at time instant $w_{z_{p-1}}>=w_{z_{p-1}^{\prime}}$ and at node $z_{p}$ 
all solutions are deleted where activities in $J$ start earlier than at time $\mathrm{w}_{\mathrm{Z}_{\mathrm{p}}}>\mathrm{w}_{\mathrm{z}_{\mathrm{p}-1}}>=$ $w_{z_{p}-1}$. Therefore, all solutions that are deleted from $\Omega_{z_{p-2}}$ in node $z_{p-1}^{\prime}$ are a subset of the solutions that are deleted from $\Omega_{\mathrm{p}-2}$ in nodes $\mathrm{z}_{\mathrm{p}-1}$ and $\mathrm{z}_{\mathrm{p}}$. Thus, we have that $\Omega_{z_{p}}$ is a subset of $\Omega_{z_{p-1}^{\prime}}$ and node $z_{p}$ can be fathomed as any solution found by branching from $z_{p}$ can also be found by branching from $z_{p-1}^{\prime}$.

The fact that $\mathrm{D}_{\mathrm{z}_{\mathrm{p}-1}^{\prime}}=\mathrm{J}+\mathrm{X}$ isn't necessarily minimal is no objection to the proof of this theorem. If $D_{z_{p}^{\prime}-1}$ is a non-minimal delaying alternative, then a minimal delaying alternative $D_{z}{ }_{p-1}$, which is a subset of $D_{z_{p}^{\prime}-1}$, can easily be constructed. As it can be proven (see proof of theorem 2) that $\Omega_{\mathrm{z}_{\mathrm{p}-1}^{\prime}}$ is a subset of $\Omega_{\mathrm{z}^{\prime \prime}}{ }_{\mathrm{p}-1}$ and as we have proven in the previous paragraph that $\Omega_{z_{p}}$ is a subset of $\Omega_{z_{p-1}^{\prime}}$, we have that $\Omega_{z_{p}}$ is a subset of $\Omega_{z_{p}}{ }_{p-1}$ and node $z_{p}$ is dominated by a node $z^{\prime \prime}$-1 with a minimal delaying alternative.

\section{ACKNOWLEDGEMENT}

The authors are greatly indebted to Professor James H. Patterson, Indiana University and Professor W. Simpson, Air University. Without their cooperation and insistance in providing us with the source data for the modified 110 test problems, this paper would not have been possible. 


\section{REFERENCES}

BALAS, E. 1970. Project Scheduling with Resource Constraints. Applications of Mathematical Programming Techniques (Beale ed.). American Elsevier, New York.

BELL, C. E., AND K. PARK. 1990. Solving Resource-Constrained Project Scheduling Problems by A* Search. Naval Res. Logist. Quart. 37, 61-84.

BOWMAN, E. H. 1959. The Schedule-Sequencing Problem. Opns Res. 7, 621-624.

BRAND, J. D., W. L. MEYER AND L. R. SCHAFFER. 1964. The Resource Scheduling Problem in Construction. Civil Engineering Studies, Report No. 5. Dept. of Civil Engineering, University of Illinois, Urbana.

CARLIER, J., AND B. LATAPIE. 1991. Une Méthode Arborescente pour Résoudre les Problèmes Cumulatifs. R.A.I.R.O.R.R.O. 25, 311-340.

CARRUTHERS, J. A., AND A. BATTERSBY. 1966. Advances in Critical Path Methods. Opnl. Res. Quart. 17, 359-380.

CHRISTOFIDES, N., R. ALVAREZ-VALDES AND J. M. TAMARIT. 1987. Project Scheduling with Resource Constraints : A Branch-and-Bound Approach. Eur. g. Opnt. Res. 29, 262-273.

DAVIS, E. W. 1966. Resource Allocation in Project Network Models - A Survey. g. Indust. Eng. 17, 177-188.

DAVIS, E. W. 1973. Project Scheduling Under Resource Constraints - An Historical Review and Categorisation of Procedures. AIIE Trans. 5, 297-313. 
DAVIS, E.W., AND G. E. HEIDORN. 1971. An Algorithm for Optimal Project Scheduling Under Multiple Resource Constraints. Mgmt. Sci. 17, 803-816.

DEMEULEMEESTER, E., AND W. HERROELEN. 1991. A Branch-and-Bound Procedure for the Multiple Resource-Constrained Project Scheduling Problem. Accepted to appear in Mgmt Sci.

DE WIT, J., AND W. HERROELEN. 1990. An Evaluation of Microcomputer-based Software Packages for Project Management. Eur. 9. Opnl. Res. 49, 102-139.

ELMAGHRABY, S. E. 1967. The Sequencing of N Jobs on M Parallel Processors. Unpublished Paper, North Carolina State University, Raleigh.

ELMAGHRABY, S. E., AND J. KAMBUROWSKI. 1989. The Analysis of Activity Networks under Generalized Precedence Relations (GPR's) - Part I. OR REPORT NO. 231. Graduate Program in OR, North Carolina State University at Raleigh.

ELMAGHRABY, S. E., AND J. KAMBUROWSKI. 1989. The Analysis of Activity Networks under Generalized Precedence Relations (GPR's) - Part II. OR REPORT NO. 232. Graduate Program in OR, North Carolina State University at Raleigh.

FRENCH, S. 1982. Sequencing and Scheduling : An Introduction to the Mathematics of the go6-shop. Ellis Horwood Limited.

HERROELEN, W. S. 1972. Resource-Constrained Project Scheduling - The State of the Art. OpnL. Res. Quart. 23, 261-275. 
JOHNSON, T. J. R. 1967. An Algorithm for the Resource Constrained Project Scheduling Problem. Unpublished Ph.D. Dissertation. Massachusetts Institute of Technology.

McCOY, P. F. 1972. Project Scheduling with Limited Resources by Extreme Point Enumeration. Presented at the 42nd National ORSA, TIMS and AIIE Meeting, Atlantic City.

MODER, J. J., C. R. PHILLIPS AND E. W. DAVIS. 1983. Project Management with CPM, PERT and Precedence Diagramming. Van Nostrand Reinhold Company.

MOODIE, C. L., AND D. E. MANDEVILLE. 1966. Project Resource Balancing by Assembly Line Balancing Techniques. J. Indust. Eng. 17, 377-383.

PATTERSON, J. H. 1984. A Comparison of Exact Procedures for Solving the Multiple Constrained Resource Project Scheduling Problem. Mgmt. Sci. 30, 854-867.

PATTERSON, J. H., AND W. D. HUBER. 1974. A Horizon-Varying Zero-One Approach to Project Scheduling. Mgmt.Sci. 20, 990-998.

PATTERSON, J. H., AND G. ROTH. 1976. Scheduling a Project Under Multiple Resource Constraints : A Zero-One Programming Approach. AIIE Trans. 8, 449-456.

PETROVIC, R. 1968. Optimization of Resource Allocation in Project Planning. Opns. Res. 16, 559-586.

PRITSKER, A. B., L. J. WATTERS AND P. M. WOLFE. 1969. Multiproject Scheduling with Limited Resources: A Zero-One Programming Approach. Mgmt. Sci. 16, 93-108. 
SCHRAGE, L. 1970. Solving Resource-Constrained Network Problems by Implicit Enumeration - Nonpreemptive Case. Opns. Res. 10, 263-278.

SHACKLETON, N. J. 1973. Minimization of Project Duration When Resources are Limited. Presented at the 43rd National ORSA Meeting, Milwaukee, Wisconsin.

SIMPSON, W. P. 1991. A Parallel Exact Solution Procedure for the ResourceConstrained Project Scheduling Problem. Unpublished Ph.D. Dissertation. Indiana University.

STINSON, J. P. 1976. A Branch-and-Bound Algorithm for a General Class of Multiple Resource-Constrained Scheduling Problems. Unpublished Ph.D. Dissertation. North Carolina State University, Raleigh.

STINSON, J. P., E. W. DAVIS AND B. M. KHUMAWALA. 1978. Multiple Resource-Constrained Scheduling Using Branch-and-Bound. AIIE Trans. 10, 252-259.

TALBOT, B., AND J. H. PATTERSON. 1978. An Efficient Integer Programming Algorithm with Network Cuts for Solving Resource-Constrained Scheduling Problems. Mgmt. Sci. 24, 1163-1174.

WIEST, J. D. 1964. Some Properties of Schedules for Large Projects with Limited Resources. Opns. Res. 12, 395-418. 


\section{Figure captions}

Figure $1:$ Conversion of precedence relations

Figure 2: Network of problem example

Figure 3 : Network of problem example with converted precedence relations

Figure 4 : Branch-and-bound tree for problem example

Figure 5 : Resource profiles of optimal solution 


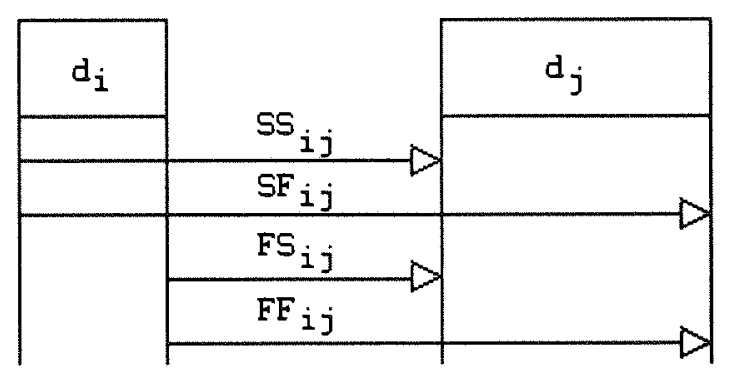

Figure 1 : Conversion of precedence relations 


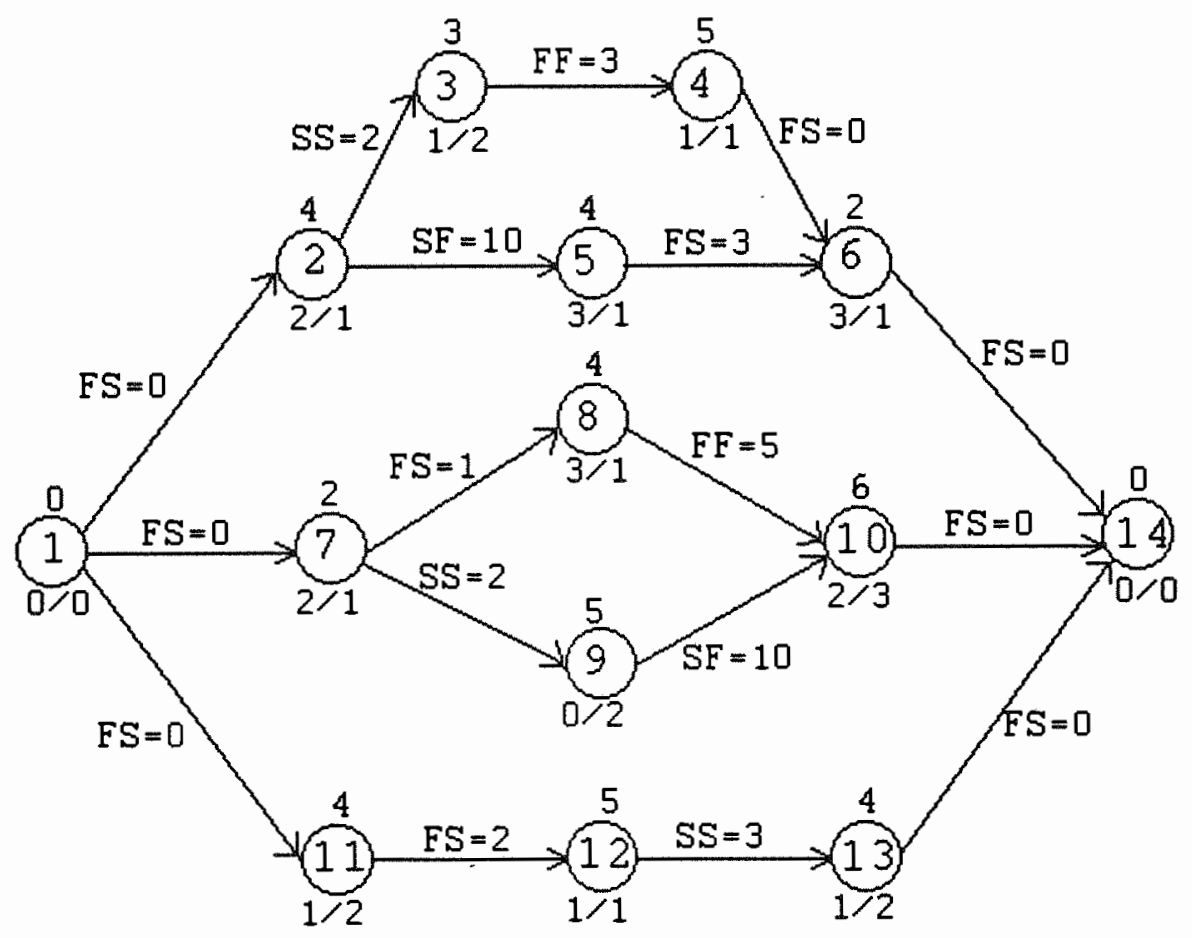

Figure 2 : Network of problem example 


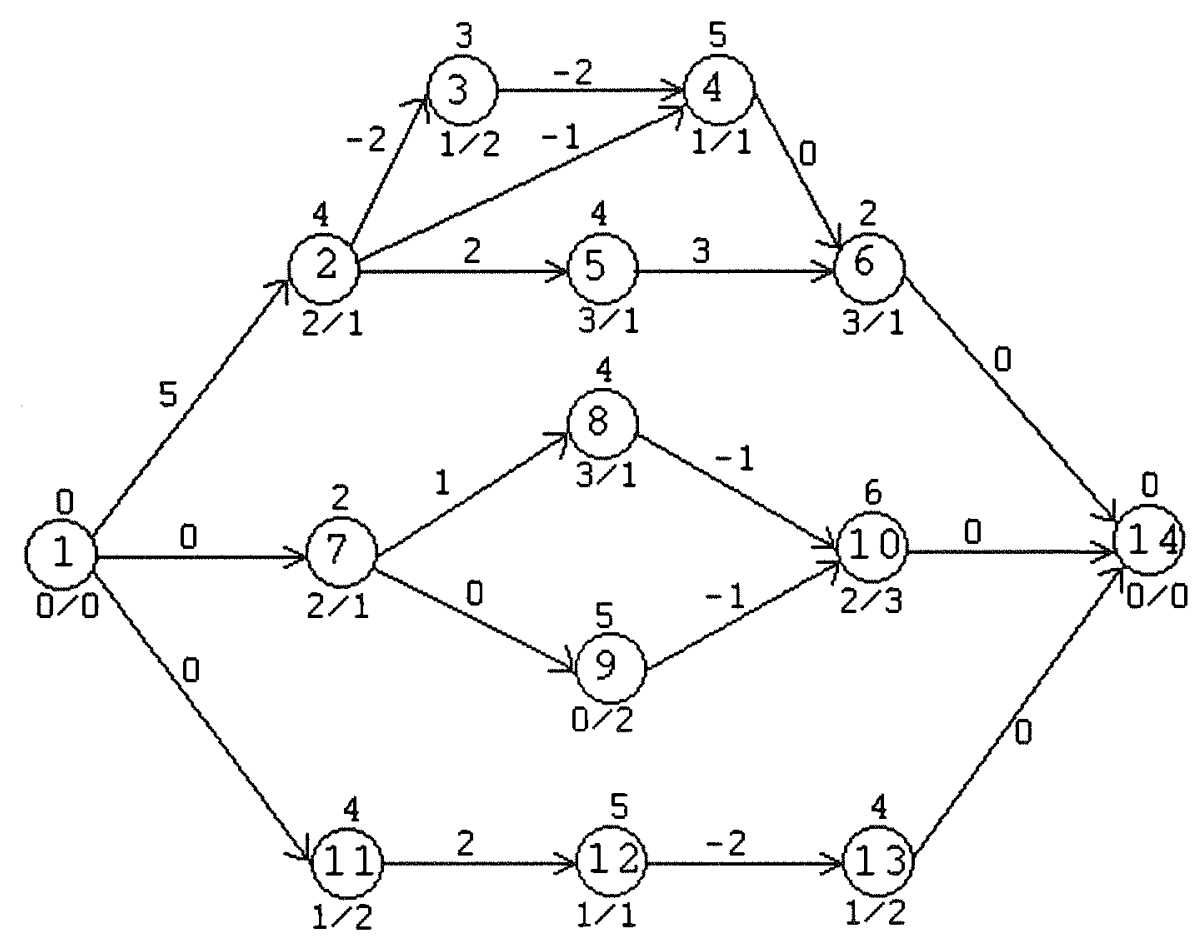

Figure 3 : Network of problem example with converted precedence relations 


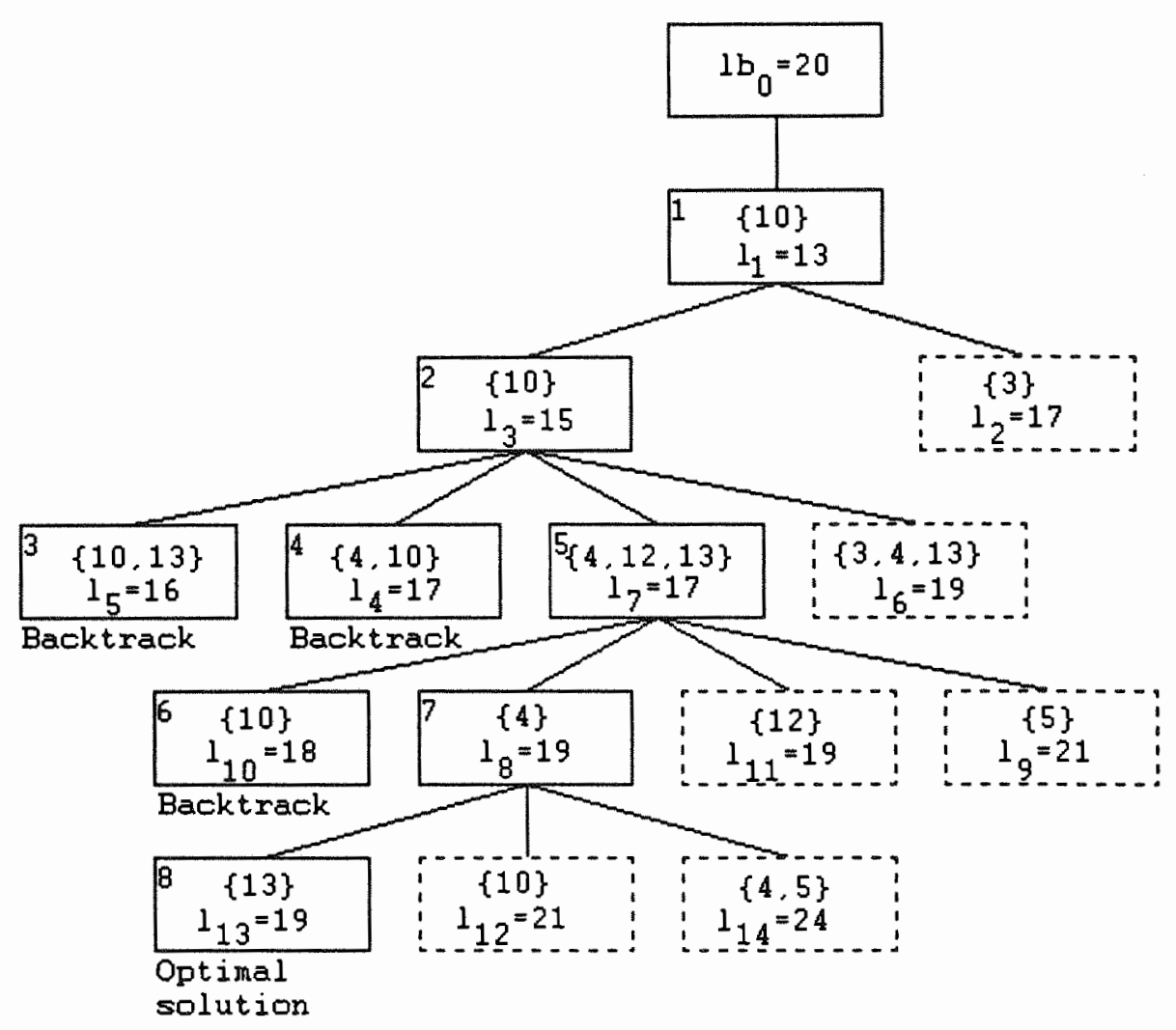

Figure 4 : Branch-and-bound tree for problem example 


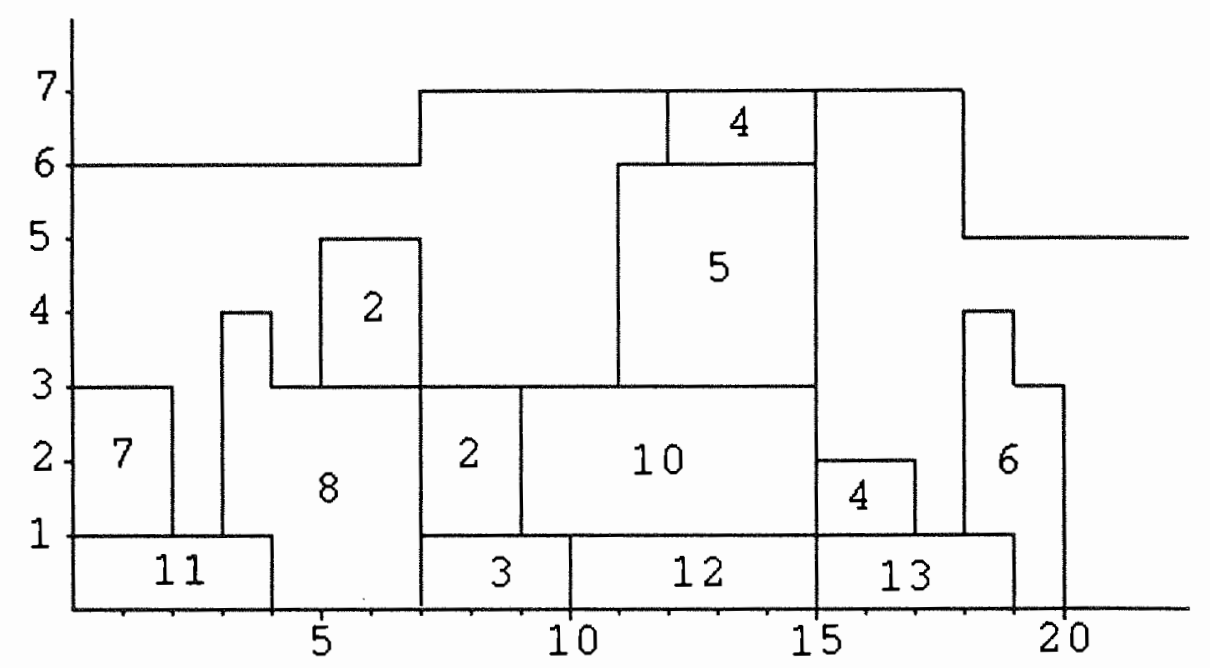

Figure 5a : Resource profile for type 1

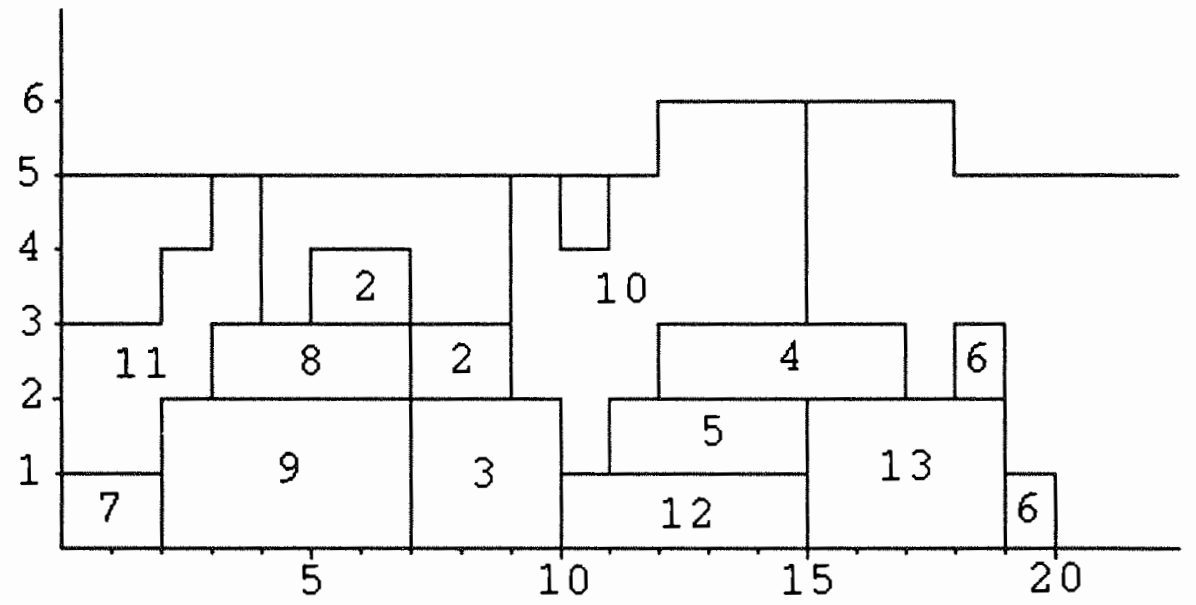

Figure $5 b$ : Resource profile for type 2

Figure 5 : Resource profiles of optimal solution 


\section{Table captions}

Table I : Resource availabilities for example problem

Table II : Computational experience on the Simpson problem set

Table III : The impact of additional constraints on computational efficiency 


\begin{tabular}{|c|c|c|}
\hline $\begin{array}{c}\text { Time } \\
\text { interval }\end{array}$ & $\begin{array}{c}\text { Availability } \\
\text { type 1 }\end{array}$ & $\begin{array}{c}\text { Availability } \\
\text { type 2 }\end{array}$ \\
\hline $0-7$ & 6 & 5 \\
\hline $7-12$ & 7 & 5 \\
\hline $12-18$ & 7 & 6 \\
\hline $18-$ end & 5 & 5 \\
\hline
\end{tabular}

Table I : Resource availabilities for example problem 


\begin{tabular}{|c|c|c|c|c|}
\hline \multirow[b]{2}{*}{ Methodology } & \multicolumn{3}{|c|}{ Variable resource availabilities } & \multirow{2}{*}{$\begin{array}{c}\begin{array}{c}\text { Constant res. } \\
\text { availabilities }\end{array} \\
\text { Demeulemeester } \\
\text { and Herroelen }\end{array}$} \\
\hline & $\begin{array}{l}\text { Simpson } \\
\text { (serial) }\end{array}$ & $\begin{array}{l}\text { Simpson } \\
\text { (parallel) }\end{array}$ & $\begin{array}{c}\text { Demeulemeester } \\
\text { and Herroelen }\end{array}$ & \\
\hline Computer used & IBM 3090 & IBM 3090 & IBM PS/2 70/A21 & IBM PS/2 70/A21 \\
\hline Problems solved & 97 & 98 & 110 & 110 \\
\hline Avg. comp. time & 100.85 & 96.63 & 1.2329 & 0.215 \\
\hline Standard deviation & 199.62 & 195.90 & 2.3133 & 0.314 \\
\hline
\end{tabular}

${ }^{*}$ Results taken from Demeulemeester and Herroelen (1991)

Table II : Computational experience on the Simpson problem set 


\begin{tabular}{|c|c|}
\hline Problem specification & Computation time \\
\hline Standard problem & 1.59 \\
\hline $\mathrm{h}_{18}=27 ; \mathrm{h}_{22}=35$ & 0.27 \\
\hline $\mathrm{g}_{4}=3 ; \mathrm{g}_{7}=10$ & 0.27 \\
\hline Increase resource availability & 0.33 \\
\hline Allow more overlapping & 10.11 \\
\hline $\mathrm{h}_{10}=24 ; \mathrm{h}_{13}=23$ & 0.39 \\
\hline $\mathrm{g}_{10}=22 ; \mathrm{g}_{13}=19$ & 0.16 \\
\hline Lower resource availability & 0.22 \\
\hline Allow more overlapping & 0.39 \\
\hline $\mathrm{h}_{22}=$ infinity & 3.30 \\
\hline
\end{tabular}

Table III : The impact of additional constraints on computational efficiency 